\title{
A Comparative Study on the Color Techniques of Chinese and Russian Ice and Snow Oil Painting Arts*
}

\author{
Lei Song \\ Heihe University \\ Heihe, China 164300
}

\author{
Huixin Chi \\ Heihe University \\ Heihe, China 164300
}

\author{
Yang Liu \\ Heihe University \\ Heihe, China 164300
}

\begin{abstract}
At the end of the 19th century, the "ambulant school" period was the heyday of the development and innovation of Russian ice and snow oil painting artistic color techniques. Looking at the works of masters of ice and snow oil paintings in all periods of Russian art, people can feel the exquisite color techniques of ice and snow oil paintings. Russian ice and snow oil paintings have a unique and noble status in the world's art history. The art color technique of Chinese ice and snow oil painting is mainly based on the "Chinese painting" element. It also draws on the continuous development of the art color technology of ice and snow oil painting in many western countries. In today's Chinese ice and snow oil painting, the color techniques are continuing to develop in the direction of the combination of Chinese and Western. The promotion and interaction of Chinese and Russian ice and snow oil painting art color technology comparative research issues and the promotion Chinese and Russian art exchange and cooperation have become important research topics.
\end{abstract}

Keywords-China and Russia; ice and snow; oil painting art; color technique

\section{INTRODUCTION}

Chinese and Russian ice and snow oil painting artistic color techniques not only have common features in the process of continuous development and innovation today, but also have individualized ice and snow oil painting artistic color technique language under the influence of different national conditions and history. Ice and snow color technique is a special technique expression method in oil painting color technique to express China and Russia's respective skills and artistic color expression methods for ice and snow oil painting art. Through the contrast of color, relationship, composition, light and dark, etc., the art and language of ice and snow oil painting techniques can be found, and there are differences between the two countries in ice and snow oil painting art techniques, expressions, as well as their

*Project: This article is a youth project of Heilongjiang Province's Philosophy and Social Science Research Plan, "Comparative Study on the Creation of Chinese and Russian Ice and Snow Oil Painting Arts" Project No.: 16YSC01. innovative characteristics of ice and snow oil painting artistic color techniques.

The development process of Russian art history and its oil painting art color technique language is very complete. From the 13th century to the 14th century, the change from classicalism to romanticism, to the development of impressionism until heyday of the "ambulant school" in the end of the 19th century, the occurrence and development of Russian oil painting art color technique language has also come a long way. At the end of the 19th century, Russia's ice and snow oil paintings in the period of the "ambulant school" were mainly developed with realistic expression techniques. Most of the color techniques were mainly quiet gray tones. The color expression was strong and the levels were rich in changes. For example, the Russian oil painting landscape master Levitan at the end of the 19th century, most of his ice and snow oil paintings represent the peaceful and sound natural landscape of the Russian winter countryside. Most of the works are mainly in cold gray tones, using the perspective relationship of the flat distance to express the composition of three-distance relationship in the picture. The overall poetic and artistic mood of the paintings is full of infinite imagination. Russian ice and snow oil paintings mostly use "rural ice and snow" as the main creative theme, and many are known as "forest ice and snow singers". The creative masters of ice and snow landscape oil paintings praised the beautiful ice and snow scenery of the countryside and drew a lot of outstanding ice and snow oil paintings.

\section{HARMONY AND UNITY BETWEEN HUE AND COLOR IN RUSSIAN ICE AND SNOW PAINTING ART}

The hue in the Russian ice and snow oil painting arts is one of the special technical expressions of color in the painting expression, and it is also a large color effect in the Russian ice and snow oil painting arts. The hue in Russian ice and snow oil painting arts is like the concept of tone in music. The harmonious tone gives people a beautiful enjoyment. The hue in Russian ice and snow oil painting arts not only plays a great role in expressing time, ice and snow environment, atmosphere, etc., but also plays a great role in 
setting the artistic themes of ice and snow oil paintings. The uniformity of hues in Russian ice and snow oil painting art is extremely important. Even if the colors are not coordinated with each other, they can be coordinated well. If the sum of the colors in the Russian ice and snow oil painting art determines the entire hue, then the entire hue determines the feeling of each color. For Russian ice and snow oil paintings, there is a very complicated connection between composition and the entire hue.

The thick hues in Russian ice and snow oil painting arts express a sense of heaviness. If there are a large number of thick hues at the bottom of the picture, it will make people feel peaceful and quiet: while when in the upper part of the picture, it will give people a gloomy and unauspicious feeling. Since life comes from sunlight, people always like to be close to the brightness since ancient times; the highlights of the paintings in Russian ice and snow oil painting art have always attracted people's attention. If the lines and hue on the screen lead people's attention to the subject, painting will definitely make a deep impression. However, if they don't play this role, or only one of them-it works, the moving effect will be weakened.

In the Russian snow and ice oil painting artist Kuinji's oil painting "The Snowy Peaks of the Caucasus", the contrast between red, blue, yellow, and green is strong, but they echo each other to produce a rapid rhythm to emphasize the march of the festival. The colors are intertwined in colorful decorative strips. But despite this colorfulness, the painter has created a uniform color value. He covered the entire scene of the Caucasus snow peaks with orange-yellow mist, depicting the gray and brown exposed snow peaks in the foreground with similar colors of snow and ice. Kuinji, the master of Russian ice and snow oil painting, expressed his vision of color with amazing skills and produced a high illusion of real life events. Thus, the profound theme of this painting has been brilliantly reflected.

\section{ANALYSIS OF COLOR CONFIGURATION IN CHINESE ICE AND SNOW OIL PAINTING ARTS}

The so-called color configuration in Chinese ice and snow oil painting arts is actually the role of color in Chinese ice and snow oil painting art in composition and juxtaposition with two or more colors, resulting in a clear and distinctive performance effect. The choice of hue, the size of the area, and their configuration and contrast in the Chinese ice and snow oil painting arts are the determinants of color performance in the Chinese ice and snow oil painting arts.

One of the important principles of composition is to create a balance of color layout in Chinese ice and snow oil painting arts. In order to achieve the color balance in Chinese ice and snow oil painting art, the vertical axis in the frame is necessary. The weight of the color gamut in Chinese ice and snow oil painting works on both sides of the axis. When Chinese ice and snow painters seek to determine the value of the "left side" and "right side" in a painting, they naturally think of human bodies. Generally speaking, people always use the right hand to write and work, and the left hand is used less. Therefore, the right side means vitality, while the left side is more passive. The right side tends to be forward and upward, and the left side is backward and downward. Many Chinese ice and snow painters' works mostly start from the lower left side, and then develop the movement to the upper right. This is in line with human visual psychological habits. If it was in the opposite, a reverse stimulating effect is produced. Therefore, when people are composing the composition in the painting art of ice and snow, they can consciously use it to produce the envisioned painting effect. Bruegel's oil painting "Hunter in the Snow" is an example. Its composition is from the upper left to the lower right. As it imagined, whether people can change it so that those who are blind go from the upper right to the lower left, the effect will inevitably entice the viewer to look at them continuously with an upward habit, and the effect of falling will be lost.

The role of color in composition in Chinese ice and snow oil painting art also lies in its brightness. The greater the difference in lightness between color and background in the art of Chinese ice and snow oil painting, the more prominent the "color" on a colored background. Although the differences in hue and color purity in Chinese ice and snow oil painting arts also have a role, they are secondary to brightness. For example, people write saturated green words on saturated red paper. It must be very eye-catching when reading, and it will be very difficult to read. If others look at it for a while, they will feel that the eyes are not comfortable. The relationship is greater than the difference in brightness between the two colors. If it has been changed and still written in light green, light red, or yellow, white on saturated red paper, it will be much more comfortable to read, and it will be clear at a glance. This is because the brightness is changed. If people understand this principle in Chinese ice and snow oil painting arts, they can apply it to composition processing.

In the long distance, Chinese ice and snow oil paintings are most conspicuous with black on a yellow background and green on a black background, followed by red and blue on a white background, then followed by red on a blue background and black on a white background.

The composition of Chinese ice and snow oil paintings must not only take into account the primary and secondary arrangements of the picture space, but also carefully design all aspects and various ice and snow oil painting elements. In terms of the color of Chinese ice and snow oil paintings, in addition to the issues discussed above, the color component of Chinese ice and snow oil paintings is also significantly important. If people put heavy colors on one side of the composition and put light colors on the other side, it will cause a sense of uneven composition. The lightness and weight of the colors of Chinese ice and snow oil paintings are consistent with the lightness of the colors. The darker colors are heavier than the lighter colors, for example, brown is heavier than yellow. Sometimes it is also related to the association of psychological factors. For example, seeing black is associated with steel and charcoal, and light blue and white are associated with light smoke, weather and snowflakes. 
It can always be seen of how the Chinese ice and snow oil painter configured his colors on a snow and ice picture according to his ideas, and formed the vivid color rhythm, thereby strengthening the whole of the idea and creating a unified "snow and ice oil painting rhythm process". "Here, one hue of ice and snow oil painting ends and another hue begins, so the shape, distance, and attitude of each subject, the most perceptual and most spiritual things are fully expressed in this hue change."

The harmony of colors in the artistic creation of Chinese ice and snow oil paintings is actually a matter of personal aesthetics of Chinese ice and snow oil painters. It is said that the collection of colors of some snow and ice oil paintings is only harmonious if it can give people a comfortable feeling, because people are used to thinking that colors in nature are "comfortable". An unwritten norm has been formed, that is, there should be no obvious conflict when various colors are matched with each other. Just as the French saying goes, "There is no need to argue about aesthetics and color."

In the hue and method of Chinese ice and snow oil painting artistic creation, if similar colors are used, when three or five adjacent colors are selected in the range of the color wheel to easily achieve coordination, and more than seven colors will tend to contrast factors in the ice and snow oil painting artistic creation. Beginners who are studying the art of Chinese ice and snow oil paintings, if they want to create impressive ice and snow oil paintings, they must learn the composition of colors in order to use the Chinese ice and snow oil painting art creation color configuration to obtain a good color effect of ice and snow oil painting.

\section{CONCLUSION}

In short, through a comparative theoretical study of color techniques in Chinese and Russian ice and snow oil painting arts, it can be deeply understood and dug out of the use of colors and emotional expressions in Chinese and Russian ice and snow oil paintings. It will also allow people to absorb nutrients and learn from each other in the color techniques of the excellent ice and snow oil painting arts of the two countries, and go further and further on the road of inheritance and development in the Chinese and Russian ice and snow oil painting arts.

\section{REFERENCES}

[1] B. Manin. Russian landscape [M]. 200. (in Russian)

[2] Smirnov, G.B. Drawing and painting of the landscape / G.B. Smirnov [M]. L.Vysh. wk1975. (in Russian)

[3] Shorokhov, V.E. Basics of composition: textbook. Benefit zz [M]. Education 197. (in Russian)

[4] Chen Luojia, Outline of Foreign Art History [M]. Southwest China University Press, 1995. (in Chinese)

[5] V.A. Merzlyakov, Through the Four Seasons - Oil Painting Landscape Creation [M]. Guangxi Fine Arts, 2011.

[6] Song Lei, On Russian Teachers' Oil-painting Teaching Methods [J]. Journal of Heihe University, vol.7, 01, 2016. (in Chinese)

[7] Song Lei, A Comparative Study of the Creative Styles of Broad River Ice and Snow Oil Paintings Between China and Russia [J]. Heihe Journal, 05, 2017. (in Chinese) 